\title{
La ciudad resignificada por la memoria: el blog y la fanpage "Maria do Resguardo"
}

\section{The city resignified by memory: blog and fanpage "Maria do Resguardo}

\author{
Rafaella Rabello* \\ Universidade Federal de Juiz de Fora, Brasil. \\ rafaella_prata@hotmail.com
}

\author{
Christina Musse** \\ Universidade Federal de Juiz de Fora, Brasil. \\ musse@terra.com.br
}

Resumen El objetivo del artículo es analizar la concepción de la memoria espacial y sentimental de publicaciones en el blog y en la fanpage de Facebook "Maria do Resguardo" creados en 2009. Develamos las múltiples representaciones de la ciudad de Juiz de Fora, Minas Gerais, expuestas en las fotografías publicadas de esta "ciudad imaginaria" reconstruida en la red social a través de imágenes expuestas virtualmente. Proponemos una línea teórica acerca de los ejes de discusión que el tema suscita: los lugares de la memoria, el espacio urbano y su representación, el blog y el Facebook como espacios narrativos de la virtualidad, que resignifican la ciudad real y las relaciones de los ciudadanos con el espacio público. Utilizamos autores de los Estudios Culturales, investigadores de historia y memoria para estudiar el pasado, y el análisis de contenido para evaluar el objeto.

\begin{abstract}
The article has the goal to analyze the conception of the spatial and sentimental memory of postings in the blog and Facebook fanpage of "Maria do Resguardo", which were created in 2009. We seek to reveal the multiple representations of the city of Juiz de Fora, Minas Gerais, exposed in the photos posted in this "imaginary city", rebuilt in the social network through the photogaph. We propose a theoretical line about the discussion axes that the subject raises: the places of memory; the urban space and its representation; the blog and Facebook as narrative spaces of virtuality, that bring new meanings to the real city and the relationship between citizens and the public space. We use authors of Cultural Studies, researchers of history and memory to study the past, and the content analysys to evaluate the object.
\end{abstract}
Palabras clave
Key words

Comunicación, Ciudad, Memoria, Facebook, Blog. Communication, City, Memory, Facebook, Blog.

\footnotetext{
* Doctoranda en Comunicación, Master en Comunicación, periodista y licenciada en Letras por la Universidad Federal de Juiz de Fora.

** Doctora en Comunicación y Cultura, y periodista de la Universidad Federal de Río de Janeiro.
} 


\section{Introducción}

Juiz de Fora es una ciudad brasileña situada en el interior del estado de Minas Gerais. Se ubica a una distancia de 283 kilómetros al sureste de la capital (Belo Horizonte) y a 180 kilómetros de Río de Janeiro; no posee litoral. Su población, de acuerdo con el conteo 2010 del Instituto Brasileño de Geografía y Estadística', es de 516.247 habitantes, siendo así la cuarta ciudad más poblada de Minas Gerais y la trigésimo sexta de Brasil. Podría ser uno más de los 5.570 municipios brasileños, pero se destaca en la historiografía reciente por haber ocupado, a principios del siglo XX, el primer lugar entre las localidades más industrializadas del país. Además, en 1964, fue escenario del golpe militar que hundió a Brasil en 21 años de dictadura. Es una ciudad compleja, cuyos sentidos no se dejan aprisionar con facilidad. Su población se caracteriza por una significativa producción cultural que parece resignificar el espacio público, característica que va en ascenso debido al acceso a las nuevas formas de comunicación, en especial a las redes sociales.

De este modo, el objetivo de este trabajo se centra en entender de qué forma el blog y la fanpage "Maria do Resguardo" actúan en la producción de las "localidades" o "lugares", entendidos como "mundos de la vida constituidos por asociaciones relativamente estables, historias relativamente conocidas y compartidas y espacios y lugares reconocibles y colectivamente ocupados" (Appadurai, 2008: 21). El autor hindú apunta la "imaginación" como la gran responsable de recrear las relaciones de pertenencia en un mundo globalizado y desterritorializado, en el cual las identidades dependen menos de las fronteras establecidas por los Estados-Nación y más de las relaciones de las comunidades con los miedos y deseos generados por los medios de comunicación.

En ese sentido las narrativas producidas por los medios de comunicación pueden rescatar la función que los cuentos, la música y la literatura, en general, han tenido en otros momentos de la historia, recreando la identificación con los vínculos entre poblaciones apartadas geográficamente de sus orígenes, pero unidas en las ciudades por recuerdos comunes. Algo que Benedict Anderson identificó como comunidades imaginadas (Anderson, 1989), donde los lazos culturales, muchos de ellos dictados por los medios de comunicación, generarían fuertes lazos de pertenencia. En este artículo, se investiga cómo las redes sociales pueden crear nuevas narrativas sobre la ciudad con la producción de una comunidad imaginada, es decir, queremos averiguar cómo el blog y la fanpage "Maria do

1 Ver IBGE: http://www.ibge.gov.br/home. Consultado el 2 de marzo de 2014. 
Resguardo" crean una Juiz de Fora imaginaria, desde nuevos lazos de pertenencia entre los usuarios de internet y el espacio público.

\section{Los medios y las narrativas sobre las ciudades}

Nos parece importante el papel de la radio y la televisión en el escenario de la segunda mitad del siglo XX en América Latina. A través de la "dramatización de lo real" (MartínBarbero, 1997: 318), los medios recrearon lazos de pertenencia entre aquellas poblaciones que habían sido obligadas a migrar de su lugar de origen para ocupar las periferias de las grandes ciudades. Pero si los medios de comunicación masiva fueron los responsables de forjar identidades nacionales, como aquella pretendida por la mayor red de televisiva de Brasil, Red Globo, que cumplió medio siglo de actividades en 2015; al mismo tiempo, el discurso manejado por ellos mismos no ofreció respuestas a la mayoría de la población marginada, que enfrentaba el acoso del mercado de consumo y el deseo de verse representada (Musse, 2008). Son esos habitantes de ciudades grandes y medianas que, a principios del siglo XXI, en medio a los cambios políticos de Brasil, con la ascensión de la izquierda al poder, a través del Partido de los Trabajadores, y la revolución de la tecnología de la información, con la popularización de las computadoras y celulares con acceso a Internet; quienes van a constituir otro tipo de consumidor de noticias y entretenimiento: usuarios que producen información, que se reinventan a sí mismos y a los contextos en que se inscriben. En la actualidad, son las personas a través de las redes de información quienes producen sentidos en torno a la ciudad y crean relaciones de pertenencia al compartir relatos. En el caso específico de este artículo investigamos las fotos antiguas compartidas por usuarios/as en la web.

La elección del objeto de investigación se justifica porque la tradición visual de Juiz de Fora tiene en la fotografía una de las formas más expresivas del registro de su cotidianidad desde los tiempos del imperio brasileño. El acervo de la colección de fotografías decimonónicas del Museo Mariano Procópio es referencia para todo el país (Ferraz, 2013). Además de lo anterior, ha sido una ciudad con gran presencia en la prensa (Musse, 2008): existen fotos muy representativas de todo el siglo XX, incluso durante el golpe militar que comenzó en esta ciudad y que en 2014 celebró 50 años. En el campo audiovisual, se hace referencia a João Gonçalves Carriço (1886-1959), uno de los pioneros del cine brasileño, quien fundó en 1934 la Carriço Film y produjo cineperiódicos y documentales que retrataban la vida social y política de la ciudad; por ejemplo, las visitas del presidente Getúlio Vargas, 
fiestas populares y religiosas, eventos deportivos, además de las primeras transmisiones televisivas en Juiz de Fora.

Hay que considerar la vena memorialista de la ciudad: Pedro Nava (2012), el más grande exponente del memorialismo en Brasil, oriundo de dicha localidad, dedicó gran parte de su obra a remontar los fragmentos de su tiempo; retrata la vida en Juiz de Fora a principios del siglo XX, una Juiz de Fora imaginada, en sus calles, sus casas y sus lugares. Para la escritora Rachel Jardim (1975), también nacida en este lugar, la memoria de los olores y ruidos está presente en esta resignificación imaginaria.

\section{Las redes sociales y la resignificación de la memoria de Juiz de Fora}

El fenómeno de las redes sociales on-line es muy reciente, nació de una tendencia natural de crecimiento de internet que se relaciona con la creación de espacios de participación de usuarios. El primer signo de la evolución en esta interacción fue la aparición de los blogs; después de ello, la segunda etapa histórica fue el surgimiento de la web $2.0^{2}$. La idea por detrás del concepto de la web 2.0 es justo la posibilidad de interacción del público con internet, a través de herramientas de wikis, publicación de videos en YouTube o comentarios en sitios de noticias. Las redes sociales sustituyeron, en larga escala, la experiencia de las personas con los blogs y los comunicadores instantáneos (como MSN, ICQ), que eran los grandes atractivos de la comunicación mediada por las computadoras en la web 1.0.

Facebook fue creado el 4 de noviembre de 2004 por Mark Zuckerberg y otros alumnos de Harvard con el objetivo de conectar estudiantes de esa universidad; posteriormente, se extendió a otras universidades de Boston, de Estados Unidos, de Europa; y, finalmente, se extendió por todo el mundo (Santana, 2013). Al trabajar la fanpage de la red social, se opta por utilizar una nueva herramienta de comunicación e interacción entre las personas. Según datos divulgados por Facebook en su versión brasileña, son publicados 460 millones de fotografías mensuales en la misma (Redação Link, 2012). La plataforma es utilizada por 76 millones de brasileños, según datos del responsable de dicha red social (Gomes, 2013). Brasil es el segundo país con más usuarios que ingresan a diario en Facebook con una marca de 47 millones de personas.

En la actualidad, la fragmentación del tiempo y el espacio lleva a transformaciones constantes de identidad o hasta, como afirman ciertos autores posmodernos, a la

2 Ver Brasil Escola: http://www.brasilescola.com/informatica/web-20.htm/. Consultado el 2 de marzo de 2014. 
pérdida de la identidad fija y constante. Según el sociólogo polaco Zygmunt Bauman, la vida contemporánea altera la manera en que las personas interactúan con el tiempo y con el espacio. Según Marc Augé el término antropológico no-lugar designa "dos realidades complementarias, pero distintas. Espacios constituidos para ciertos fines (transporte, tráfico, comercio, ocio) y la relación que los individuos establecen con esos espacios" (1998: 83). Para Augé, el lugar antropológico posee tres características afines: es identitario, relacional e histórico. Basándose en Augé (1994), Bauman afirma que: “los espacios vacíos son, antes que nada, vacíos de significación" (2001:120) y discute cómo las ciudades lidian con esos espacios vacíos y defiende que cada habitante tiene un mapa mental de su propia ciudad.

En nuestra opinión, cuando un internauta utiliza viejas imágenes fotográficas para representar a su ciudad, que significa la creación de un mapa mental, él está dando un nuevo significado a la ciudad real por medio de una narrativa singular, creada por él mismo. Las páginas web pueden ser consideradas, en nuestra opinión, como lugares donde los usuarios de internet dan un sentido a su ciudad, por lo tanto, no pueden ser consideradas como "sitios vacíos", ya que, con sus aportaciones, los usuarios dan un sentido muy singular a las ciudades.

La nostalgia manifestada en la virtualidad por las páginas web que rescatan la historia y lanzan debates acerca de la antigua y la nueva Juiz de Fora nos hace recordar las ciudades y los símbolos comentados por Italo Calvino (1990). Las ciudades son códigos que presuponen una lectura (decodificación) de sus representaciones. Las instituciones son algunos de los signos que pueden ser reconocidos en las ciudades, porque existen espacios de cultura con orientaciones y reconocimientos y también territorios de identidad y pertenencia. Para Calvino, "se confirma la hipótesis de que cada persona tenga en mente una ciudad hecha exclusivamente de diferencias, una ciudad sin figuras y sin forma, rellenada por las ciudades particulares" (1990: 34).

Esa cartografía imaginaria que busca engendrar una posible legibilidad de las ciudades es expuesta por Renato Cordeiro Gomes (2008). La percepción urbana para el autor significa que la ciudad es un lenguaje dual en búsqueda de ordenación. Considera que "la memoria condiciona la lectura de la ciudad en búsqueda de sentido explícito y reconocible, que la sociedad moderna ya no permite" (2008: 44). Y complementa explicando que: "la relación homóloga entre la ciudad y la memoria se hace por la redundancia, por lo repetible, marca de la Experiencia, donde hay repetición de lo que más profundamente se olvida" (44). 
Raquel Rolnik (1998) trata la arquitectura como registro de la vida social y, como consecuencia, los propios espacios cuentan su historia:

En la ciudad escrita, habitar gana una dimensión completamente nueva, una vez que se fija en una memoria que, al contrario de los recuerdos, no se disipa con la muerte. No son solamente los textos que la ciudad produce y contiene (documentos, órdenes, inventarios) que fijan esta memoria, la propia arquitectura urbana cumple también este papel (1998: 16).

Para la elaboración de las representaciones de la ciudad ocurre una demanda de memorias colectivas a través de la preservación de bienes arquitectónicos. "Se trata de impedir que esos textos sean borrados, aunque, muchas veces, acaben por servir tan solo a la contemplación, muriendo así para la ciudad que pulsa, alrededor" (18). La manutención de la memoria de la ciudad proviene del trabajo de los ciudadanos y a través de las redes sociales los mismos intentan resignificar Juiz de Fora.

Así que podemos considerar que un ejercicio de la memoria es pertinente en generaciones que se acostumbraron a vivir de la superficialidad, de la fragilidad, del inmediatismo y de las rápidas transformaciones traídas con las tecnologías de comunicación utilizadas en internet, conforme nos alerta Bauman. Esa mirada sobre el pasado puede producir nuevos significados atribuidos a Juiz de Fora, que busca aclarar de qué modo los recuerdos afectan la ciudad que vive en el imaginario y, al mismo tiempo, establece otras perspectivas de la ciudad real.

La memoria de la ciudad se constituye por sucesos, lugares, personas, personajes, entre otros componentes. A través de las fotos del blog conseguimos revelaciones de grandes monumentos y sucesos de diversas épocas. En la perspectiva de Halbwachs (2003), toda memoria es "colectiva", son los grupos sociales que determinan lo que es "memorable" y las formas por las cuales se está recordando. Hasta el momento, solo los grupos hegemónicos dominaban los criterios de lo que debería ser recordado, por lo tanto, era más fácil que solo viéramos diagnosticada la memoria oficial. Ese fenómeno es sometido a transformaciones constantes.

Halbwachs cree que recurrimos a testimonios para reforzar, olvidar o para completar lo que sabemos de un evento: "[a]sí, cuando regresamos a una ciudad en la que ya habíamos estado, lo que percibimos nos ayuda a reconstituir un cuadro del que muchas partes fueron olvidadas" (2003: 29). Acerca de la memoria colectiva, el autor afirma que: 
"nuestros recuerdos permanecen colectivos y nos son recordados por otros, aunque se trate de eventos en que solamente nosotros estuvimos envueltos y objetos que solamente nosotros vimos. Esto ocurre porque jamás estamos solos" (30).

Las personas, grupos o instituciones se sienten autorizadas para compartir sus recuerdos, escribir, fotografiar, grabar o representar sus historias, por sus autores y sus testimonios: "Yo no conocía Juiz de Fora antiguamente, soy de los 70, prácticamente anterior a eso no había memoria de nada. Así que decidí saber cómo era la ciudad y eso despertó mi interés para el blog" ${ }^{\prime \prime}$. Siendo así, el blog y la fanpage "Maria do Resguardo" son un intento de rescatar la historia, por necesidad de supervivencia y reconstrucción de la memoria de una ciudad.

\section{Las redes sociales como "lugares de memoria"}

En contraposición al concepto de no-lugar, un segundo concepto que abordamos en el artículo es el de "lugares de memoria" proveniente del historiador francés Pierre Nora (1998). Pierre Nora afirma que si es necesario sacralizar la memoria es porque no existe más; cree que si aún habitáramos nuestra memoria, no tendríamos la necesidad de consagrar lugares. Los "lugares de la memoria" resultan de esta tensión entre lo vivido, lo narrado, lo registrado y lo olvidado, de la forma como la sociedad los reorganiza: "los lugares de la memoria son, antes que nada, restos. La forma extrema donde subsiste una consciencia conmemorativa en una historia que la llama, porque ella la ignora" (1998: 13). Esa reserva de memoria sirve para lo que nos sería imposible recordar.

São lugares, com efeito nos três sentidos da palavra, material, simbólico e funcional, simultaneamente, somente em graus diversos. Mesmo um lugar puramente funcional, como um manual de aula, um testamento, uma associação de antigos combatentes, só entra na categoria se for objeto de um ritual (1998: 21).

Piper, Fernández y Iñiguez (2013) también trabajan el concepto de rememoración:

En la práctica de recordar se entrelazan palabras, silencios, imágenes, artefactos, cuerpos y lugares, entre otros, y es precisamente la relación entre ellos la que contribuye a construirlos. Estas acciones reproducen interpretaciones del pasado, aunque contribuyen para transformar las condiciones que harán (o no) posible nuevos campos de sentido, y es eso precisamente lo que otorga a la memoria su poder de construir versiones contra hegemónicas (2013).

3 Entrevista en soporte audiovisual con Marcelo Lemos, en 9 de junio de 2012. 
Las nuevas significaciones dependen de lo que habita en los imaginarios de los sujetos con nuevos recuerdos u olvidos. En estos imaginarios, quedan tensionadas la subjetividad individual y los discursos hegemónicos (o contra hegemónicos), estos, selectivamente, nos indican qué recordar, creando los "lugares de memoria". En este proceso de "hacer memoria" los medios tienen un papel especial. Si no vivimos una situación particular, solamente tomaremos su conocimiento por mediación de los vehículos de comunicación. “Toda memoria está inserta en procesos de significación más amplios y, por tanto, está mediada por los símbolos e imaginarios que circulan en su sociedad y que son dinámicos y cambiantes" (2013).

Respecto del exceso de memoria y valorización del pasado, llegamos a otro concepto que nos gustaría abordar: el "exceso de memoria" preconizado por Andreas Huyssen (2000). La sensibilidad memorial desde los 80 , como observa el autor, ha llevado a los sectores relacionados con la cultura a una verdadera obsesión por el pasado. Eso ocurre porque la velocidad está destruyendo el espacio, apagando la distancia temporal. "Cuanto más memoria almacenamos en un banco de datos, más el pasado es absorbido para la órbita del presente, listo para ser accedido en la pantalla" (2000: 74). Y este exceso de información al que somos sometidos es causado por el sentimiento del miedo al olvido. Por eso, intentamos combatir ese sentimiento con estrategias de rememoración pública y privada.

Entendemos que el blog y la fanpage funcionan como lugares que congregan y almacenan las referencias de los juiz-foranos. "La memoria de los grupos, por lo tanto, parte de una forma concreta de un hecho antiguo y lo somete a constantes recreaciones que atienden a las necesidades espirituales del presente de sus integrantes" (Marcondes, 1996: 313). El autor también refleja cómo esa red social interfiere en los acontecimientos memorables:

Las tecnologías transforman la manera en que las personas recuperan y utilizan memorias. Como soportes de la memoria, funcionan como extensión de la capacidad humana de almacenar y recuperar informaciones, conocimientos y acontecimientos vividos, proyectos $y$ planes futuros (1996: 314).

Henri Bergson complementa explicando la causa de que un recuerdo se torne en imagen: "De modo general, por derecho, el pasado solo retorna a la consciencia en la medida en que pueda ayudar a comprender el presente y a prever el porvenir: es un bateador de la acción" (2006: 61). Ese boom que se está presentando en las redes sociales a través de grupos de Facebook, blogs y sites revelan la condición de angustia por la preservación de la memoria, como respuesta a la aceleración del tiempo y a la fugacidad de lo contemporáneo. 


\section{La fanpage y el blog: narrativas afectivas de la ciudad}

La fanpage "Maria do Resguardo" (Imagen 1) derivó de trabajos en el blog homónimo creado en 2009 en la ciudad de Juiz de Fora. El blog (Imagen 2) posee un rico acervo de fotografías antiguas y en él se encuentran disponibles más de 15 mil imágenes, cuenta con 315 miembros y más de un millón de accesos.

La creación del blog "Maria do Resguardo" partió de la idea de Marcelo Lemos, nacido en los años 70 y criado en Juiz de Fora. Lemos trabaja en el comercio desde hace 20 años, en una tienda de discos en el centro de la ciudad. Es ahí donde hace las publicaciones y reúne a los colaboradores y simpatizantes de la página. Hay una foto de la lápida de una mujer en la presentación del blog; su identidad no ha sido revelada a los internautas, pero se trata de la esposa de Lemos, que aún sigue viva. La moldura de la foto es apenas una broma. El nombre no es real, al blogger le gustó María y cree que la palabra resguardo remite a guardar cosas antiguas.

A Lemos siempre le gustaron las fotografías antiguas, así como los muebles, carros y otros objetos. Pero creía muy difícil conseguir imágenes porque consideraba a los coleccionistas de Juiz de Fora muy cerrados: "Creen que la historia les pertenece y que el momento en que divulgan la foto, pierde aquel encanto de la raridad, de la preciosidad. Yo no veo de esa manera. Fue así que tuve la idea de crear el blog con las fotos que tenía”. Después, los cibernautas comenzaron a proporcionarle material.

Algunos marcadores ${ }^{5}$ son utilizados para la organización del material en el blog y para facilitar la búsqueda del internauta. Los siguientes son los más relevantes: Juiz de Fora Antigua (430), Barrios (453), Av. Rio Branco (371), Vehículos (188), Escuelas (168), Rua Halfeld (143), Plazas (141), Panorámica (115), Iglesia (113), Deportes (109) y Medios (104). Como señala Rabello y Musse (2012) "en cada división, se mezclan imágenes de diversas fechas, no hay una división suficientemente clara y objetiva de fotografías, pues las publicaciones son aleatorias, de acuerdo con la subjetividad de Lemos". Para nosotras, el estudio de estos mensajes desde un enfoque "netnográfico", ha permitido una nueva interpretación de las relaciones entre los ciudadanos y el espacio público.

4 Lemos, Marcelo. Entrevista concedida a las investigadoras el 9 de junio de 2012.

5 Ver Maria do Resguardo: http://mariadoresguardo.blogspot.com.br/. Consultado el 2 de marzo de 2014. 


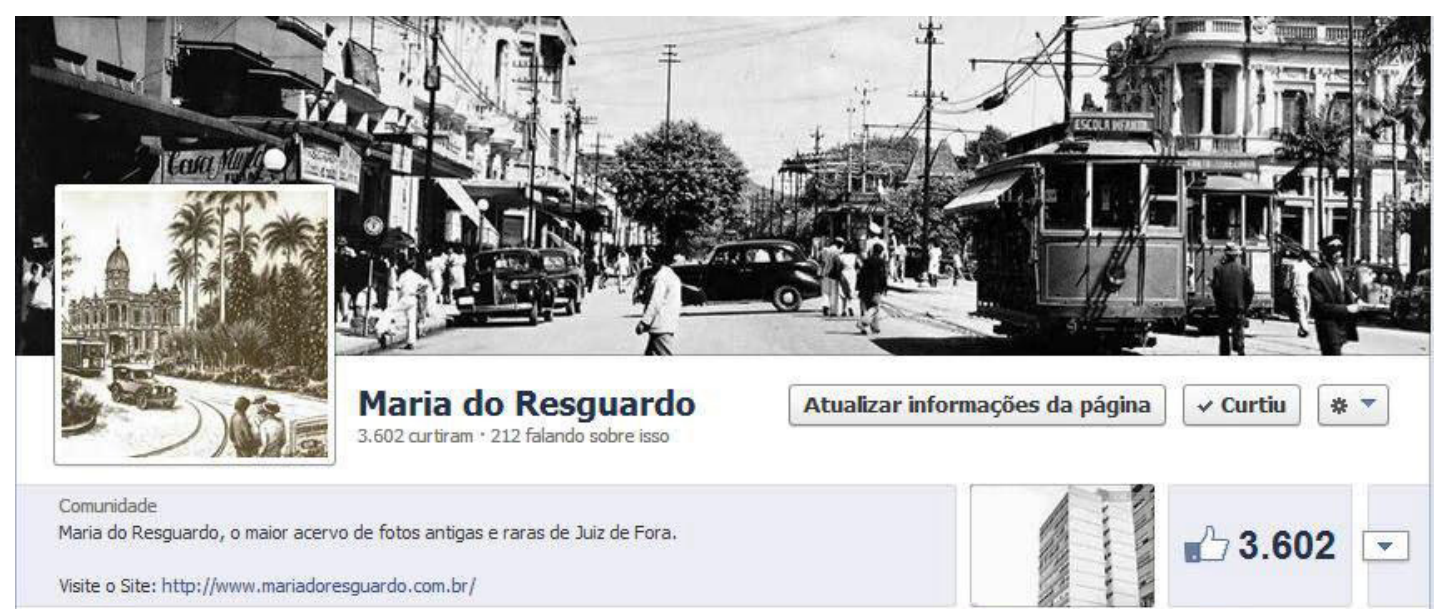

Imagen 1: captura de pantalla de la fanpage "Maria do Resguardo". Disponible en: https://www.facebook.com/MariadoResguardo.

\section{MARRIA DO PESCUIRDO}

\section{IMAGCAIIS AIITICGAS DE JIZ DE FORA}

Fotos e livros sempre acobam nas gavetas, deterioram e depolis vão para o lixo. O blog

e memórial

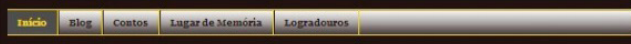

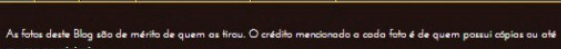

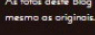

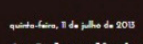
Av. Independencia, hoje Presidente Itamar
Franco, década de 1970 (arquivo de João Batista
de Araưjo) de Arauijo)
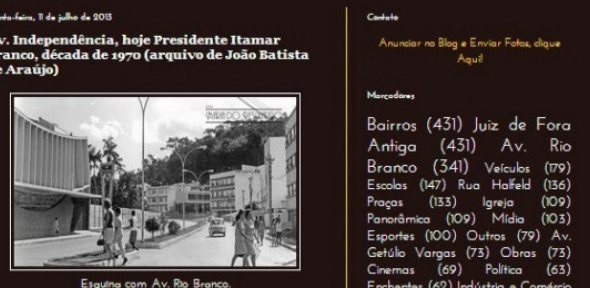

Imagen 2: captura de pantalla del blog "Maria do Resguardo". Disponible en: http://www.mariadoresguardo.com.br/.

Interacciones mediadas son la clave a través de la cual las prácticas sociales son definidas y experimentadas (Hine, 2005: 01). Teniendo el ciberespacio como un medio rico para la comunicación a partir del crecimiento del número de usuarios (Hine, 2005), las nuevas tecnologías amplían la cuestión de la multiplicidad metodológica al asociar el debate sobre los avances tecnológicos a cuestiones de sociabilidad y apropiación, por lo tanto "el agente de los cambios no es la tecnología en sí, sino las construcciones de sentido a su alrededor" (Hine, 2005: 13). La autora defiende la utilización de la etnografía transportada 
al ciberespacio como metodología para superar las dificultades técnicas del investigador acerca de los objetos investigados y de la propia limitación de algunos objetos que pueden representar barreras para superarse por medio del trabajo "netnográfico".

En la presente investigación proponemos un análisis cualitativo del material utilizando la "netnografia". Teniendo en cuenta que la postura interpretativa es parte de la composición del análisis, según el recorrido que propone Kozinets (2007), la "netnografia" está sistematizada básicamente en cuatro etapas: 1) entrée cultural, 2) recogida y análisis de los datos, 3) ética de la investigación y 4) feedback y comprobación de las informaciones (Amaral, Fragoso y Recuero, 2012: 175). Planteamos que la investigación del etnógrafo sirve para la comprensión de las experiencias y dinámicas sociales que construyen redes de significados. Según esta perspectiva metodológica la comunicación por medio de internet se refiere tanto a las formas como interactúan actores sociales y a los resultados de esas interacciones. En nuestro caso, el investigador ha observado sin intervenir en las prácticas cotidianas de la página web.

El blog cumple bien el papel tanto de exhibir los contenidos como de rescatar las memorias de su creador y de la población local. Posee cuatro coordinadores y siete colaboradores que auxilian en la selección de fotografías; tal vez por eso se explica el gran número de fotos del patrimonio, espacios públicos o de alguna región comercial, política o histórica importante del lugar. "Las personas no suben fotos de la vida privada, el enfoque es en el físico de la ciudad, en los lugares monumentales, de conmemoración" (Rabello y Musse, 2012). Hay, por ejemplo, registros de la calle Halfeld, una de las principales del centro, con galerías que lo transforman en un enorme centro comercial a cielo abierto, o de la avenida Río Branco, que es una de las más grandes de Brasil en línea recta. ${ }^{6}$

La dimensión espacial, arquitectónica y monumental de la ciudad es trabajada en el blog a través de 15 mil fotografías antiguas expuestas en blanco y negro, con visualizaciones que contabilizaron más de un millón de accesos. El imaginario de Juiz de Fora se encuentra disperso en medio de nuevas manifestaciones de la memoria virtual y colectiva, en la recuperación de algunas de las muchas identidades de la ciudad, de aquellas que son construidas con los tintes de la subjetividad.

6 Con una longitud total de 6.4 kilómetros, de los cuales 5.7 kilómetros son en línea recta. Disponible en: http://www.skyscrapercity.com/showthread.php?t=603703. Consultado el 2 de marzo de 2014. 


\section{Análisis del contenido: el colectivo de imágenes de la fanpage "Maria do Resguardo"}

Durante el proceso de investigación se hizo un análisis del contenido publicado con el objetivo de identificar las "ciudades imaginadas" por los miembros. El levantamiento de la muestra comenzó en mayo de 2014, mes de aniversario de la ciudad. Se optó por un análisis no secuencial para tener una visión más amplia del material. Así, los meses de julio y septiembre también fueron seleccionados. El número de meses contemplaba publicaciones del primer y segundo semestres, conformando un corpus que permitiera una evaluación con más criterio y que no fuera determinada o por una categoría específica de fotos que podrían estar destacadas en el periodo.

Se utilizó como metodología el Análisis del Contenido (AC) según el abordaje de Laurence Bardin (2011), en el cual el mensaje es el punto de partida del AC, sea verbal (oral o escrito), gestual, silencioso, figurativo, documental o directamente provocado. El método "es un conjunto de técnicas de análisis de las comunicaciones que utiliza procedimientos sistemáticos y objetivos de descripción del contenido de los mensajes" (2011: 44), lo que posibilita la utilización de varias herramientas metodológicas. Es importante señalar que la autora compara al analista con un arqueólogo, dado que se trabaja con vestigios de documentos y porque debe hacer inferencia de conocimientos (cuantitativos o no), en el tratamiento del material colectado, para encontrar "significados" de naturaleza psicológica, sociológica, política, histórica, entre otros.

Asimismo, en esta investigación se hizo una categorización temática de los comentarios de los miembros de la fanpage, que no es otra cosa que una operación de agrupamiento de elementos bajo títulos genéricos: el nostálgico, en el cual los usuarios exaltan un pasado glorioso de la ciudad, unido al afecto por lo monumental; el informacional, que son objetivos y ofrecen datos duros como localización, fechas y nombres de personajes; el crítico, que desprecia o está a favor de la preservación del patrimonio arquitectónico.

El número de comentarios nostálgicos es el más grande, lo que comprueba la fuerte tendencia de los "juiz-foranos" de mirar hacia el pasado de modo idealista. Para llegar a esta categoría de análisis, se optó por verificar las palabras con mayor número de repeticiones. Encontramos expresiones que hacen parte del mismo campo semántico: memoria/ recuerdo, con 11 menciones; linda/bella, con 5 menciones; demolida/derrumbada/ perdida/acabada/destruida, con 9 menciones; patrimonio/preservada, con 7 ; y triste/ lamento/nostalgia, con 13 menciones. 
Los miembros usuarios extrañan "lugares de memoria" con los que se identifican o con cuales poseen cierto sentido de pertenencia. Eso puede ser percibido a través de comentarios que hacen referencia a sitios que frecuentaron durante distintas etapas: "Viví allá durante algunos años, en etapas diferentes de mi vida" C.S.L., “Nací en este barrio en 1960...”. L.X.; "Fueron muchos paseos hasta Matías los domingos por la mañana durante mi niñez". V.G.?

Los comentarios críticos son relativos a los miembros que dejan mensajes a favor o en contra de las demoliciones del patrimonio. En estas interacciones, los internautas dejan clara su aversión al hecho de que edificios con estilos arquitectónicos antiguos fueran demolidos a causa del crecimiento inmobiliario de la ciudad, por ejemplo: "La culpa de la pérdida de esos inmuebles la tienen los herederos, quienes los venden apenas mueren sus parientes para tener una ganancia. Les queda a los funcionarios intervenir y comprar el inmueble con dinero público". A.M.

En contrapartida, algunos miembros no creen que la memoria personal deba interferir para que la gente tenga apego a las construcciones o a los monumentos, como en la cita: "Después reclaman que Juiz de Fora es una ciudad retrasada y no evoluciona. ¡Está ahí a culpa, toda de ustedes, quienes no dejan crecer la ciudad y modernizarse!", H.M. Las demostraciones de admiración por el pasado sobresalen comparadas con los comentarios que defienden el progreso.

Los comentarios informacionales aparecen de modo equilibrado, por la necesidad de referencias que tienen los miembros para activar las memorias, tales como: "Esta foto fue tomada desde la esquina de la calle Ingeniero Otto Salzer con la calle Bernardo Mascarenhas. La primera casa de la derecha es la casa de mis abuelos José Julião y Carolina Brugger Julião, número 621", J. Son recordadas fechas, rutinas de los moradores de algún barrio mencionado, nombres de personajes y curiosidades. Los usuarios parecen competir para mostrar cuál de ellos tiene más información y, por lo tanto, establecer un diálogo que reconstruye el pasado reciente.

\section{Conclusión}

El artículo se basó en la perspectiva de una memoria que reside no sólo en los registros del pasado, sino también en la resignificación del presente, y en que la Juiz de Fora del blog y

7 Citas extraídas de la fanpage "Maria do Resguardo". Los nombres de los usuarios están abreviados. 
de la fanpage "Maria do Resguardo", tal vez, pueda ser al mismo tiempo una Juiz de Fora del presente, al registrar la memoria del pasado. Las fotos antiguas, el blog y la fanpage crean un vínculo común: la resignificación espacial de la memoria de la ciudad, sus calles, sus instituciones y sus lugares. Tal como la Juiz de Fora que persistió en la memoria de Pedro Nava y de Rachel Jardim, también la Juiz de Fora presente en el blog y en Facebook es una ciudad imaginaria e imaginada. La memoria visual y al mismo tiempo la lírica de la ciudad es recreada por las fotografías presentadas en el medio virtual, permitiendo la manipulación y la reproducción de imágenes.

En las plataformas analizadas existe más uso de fotografías de lugares y monumentos que de personas, con lo que se establece un alejamiento entre lo público y lo privado. No se "publican" aspectos de la vida común, situaciones en familia o selfies, es algo muy diferente de la exposición narcisística (Sibilia, 2008) que observamos en las redes sociales en la actualidad. Parece que en ese ejercicio de memoria no existe el objetivo de definición de las identidades por las pequeñas historias, lo que prevalece es la cohesión de imágenes que revela un todo grandioso, el conocimiento objetivo del mundo.

Otra cuestión curiosa es que se encuentran pocas publicaciones de fotoperiodismo, en una ciudad en que la imprenta es fundamental para el registro de lo cotidiano. La mayoría de las imágenes no son del creador del blog o de los colaboradores, sino que pertenecen a otros autores; es interesante considerar también que no son los propios fotógrafos o sus familias quienes las "suben".

A lo largo de las observaciones virtuales se percibió que la fanpage y el blog se sincronizan y que el gestor busca constantemente promover la interacción entre ambos medios. La fanpage llega a un público más extenso sea por su diversidad o cantidad, que el blog, lo que puede ser ocasionado por las herramientas disponibles en Facebook. A través de los motores de búsqueda, los comentarios, me gusta o compartir, los usuarios difunden los temas en cuestión de segundos, a una velocidad mucho más rápida de lo que ocurriría solamente con las publicaciones del blog.

A partir de las entradas, los miembros de la fanpage manifestan las memorias individuales y discuten también la memoria colectiva. Lugares públicos, edificios, medios de locomoción y eventos son destacados cuando ya no existen más. La imposibilidad de revisitar un lugar o participar de una situación cotidiana del pasado genera una gran nostalgia entre los 
usuarios. La rememoración también sirve como motivación para buscar la preservación del patrimonio histórico/cultural de la ciudad.

Al analizar el proceso de rememoración construido en el blog y en la fanpage, queda caracterizada la utilización de estas plataformas de la web para dar nuevos sentidos al espacio público real. La recuperación de fragmentos de la ciudad registrados en las fotografías que organizan el pasado es un movimiento nostálgico que puede ser usado para la sustitución del caos del presente. El número de comentarios nostálgicos es el más grande, lo que comprueba la fuerte tendencia de los "juiz-foranos" de mirar hacia el pasado de modo idealista. Si la ciudad contemporánea crece de manera desordenada y deja en segundo plano la función de propiciar cambios afectivos entre sus habitantes, si las calles y las avenidas hoy en día no sirven más para los encuentros, sino solo para el flujo. Por lo tanto, el blog y la fanpage "Maria do Resguardo" pueden ser considerados “lugares de memoria" según el sentido que confiere Pierre Nora (1998), en lo cual la ciudad adquiere nuevos significados a partir de las narrativas que hacen sus habitantes sobre ella. Comprobamos en este artículo que las redes sociales ocupan actualmente un nuevo hogar de construcción de sentidos, no más limitados a los medios de comuncicación tradicionales. La ciudad de Juiz de Fora es resignificada por la memoria narrada por el blog y la fanpage "Maria do Resguardo".

Referencias Amaral, A., Fragoso, S. y Recuero, R. (2012). Métodos de pesquisa para a internet. Porto Alegre: Sulina. Anderson, B. (1989). Nação e consciência nacional. São Paulo: Ática.

Augé, M. (1994). Não-lugares: Introdução a uma antropologia da supermodernidade. Campinas: Papirus. Bardin, L. (2011). Análise de conteúdo. São Paulo: Ediciones 70.

Bergson, H. (2006). "A memória ou os graus coexistentes da duração". En Memória e Vida, 47-93. São Paulo: Martins Fontes.

Bauman, Zygmunt. (2001). Modernidade líquida. Rio de Janeiro: Jorge Zahar Ed., 2001.

Calvino, I. (1990). As cidades invisíveis. São Paulo: Companhia das Letras.

Ferraz, R. (2013). Colecionismo e a formação da coleção de fotografías oitocentistas no acervo do Museu Mariano Procópio - Juiz de Fora (MG). Consultado el 2 de marzo de 201IV Encontro Nacional de Estudos da Imagem. Sitio web: http://www.uel.br/eventos/eneimagem/2013/anais2013/trabalhos/ pdf/Rosane\%20Carmanini\%20Ferraz.pdf.

Gomes, H. (2013). Brasil é o $2^{\circ}$ país com mais usuários que entram diariamente no Facebook. 2 de marzo de 2014, de G1. Consultado el 2 de marzo de 2014: http://g1.globo.com/tecnologia/noticia/2013/09/ brasil-e-o-2-pais-com-mais-usuarios-que-entram-diariamente-no-facebook.html 
Gomes, R. C. (2008). Todas as cidades, a cidade: literatura e experiência urbana. Río de Janeiro: Rocco. Halbwachs, M. (2003). A memória coletiva. São Paulo: Centauro.

Hine, C. (2005) "Virtual Methods and the Sociology of CyberSocial-Scientific Knowledge". En Hine, C. (org.), Virtual Methods. Issues in Social Research on the Internet. Oxford: Berg.

Huyssen, A. (2000). Seduzidos pela memória: arquitetura, monumentos, mídia. Rio de Janeiro: Aeroplano. Jardim, R. (1975). Cheiros e ruídos: estórias. Río de Janeiro, J. Olympio; Brasilia: INL.

Kozinets, R. V. (2007). “Netnography 2.0”. En Belk, R. (ed.), Handbook of Qualitative Research Methods in Marketing.Toronto, Toronto, Canada.

Marcondes, C. (1996). Pensar-pulsar. Cultura comunicacional, tecnologias, velocidade. São Paulo, Ediciones NTC.

Musse, C. (2008). Imprensa, cultura e imaginário urbano: exercício de memória sobre os anos 60/70 em Juiz de Fora. São Paulo: Nankin; Juiz de Fora: Funalfa.

Nava, P. (2012). Baú de ossos. Sao Paulo: Companhia das Letras.

Nora, P. (1998). “Entre Memória e História: a problemática dos lugares”. En Projeto História, 17, 7-15. Sao Paulo: PUC.

Piper, l., Fernández, R. y Îniguez, L. (2013). "Psicología social de la memoria - espacios y políticas del recuerdo". Psyche. Vol 22, n.2. Santiago: Chile.

Rabello, R. y Musse, C. (2012). Maria do Resguardo: o blog como lugar da memória de Juiz de Fora. IV Encuentro Nacional de ULEPICC-Brasil-Río de Janeiro.

Redação Link. (2012). Os números do Facebook no Brasil. 2 de marzo de 2014, de Link Sitio web: http://blogs.estadao.com.br/link/os-numeros-do-facebook-no-brasil/

Rolnik, R. (1998). O que é cidade. Sao Paulo: Brasiliense.

Santana, A.L. (2013). História do Facebook. Consultado el 2 de marzo de 2014, de InfoEscola Sitio web: http://www.infoescola.com/internet/historia-do-facebook

Sibilia, P. (2008). O show do eu: a intimidade como espetáculo. Rio de Janeiro: Nova Fronteira.

Cómo citar Rabello, R. y Musse, C. (2016). "La ciudad resignificada por la memoria: el blog y la fanpage "Maria do Resguardo". Comunicación y Medios, 25 (33), 73 - 88. 